\title{
Pensamiento crítico en economía
}

El significado del pensamiento económico crítico o heterodoxo puede ser intuitivamente fácil de entender: Previsiblemente ubicado como un pensamiento de izquierda, posiblemente dentro de alguna corriente marxista. A pesar de lo anterior, su acepción puede variar significativamente según los contextos en los que se use, o según las personas que lo utilicen. Por lo tanto, su significado es equívoco.

Desde luego, si nos identificamos como personas que practicamos una economía crítica, podemos pensar a pie juntillas que este tipo de economía nos lleva a razonamientos que son necesariamente profundos y, sobre todo, verdaderos en contraposición al pensamiento económico dominante o hegemónico que no lo sería, pues este lo que busca al final es mantener el status quo -injusto-, valiéndose del encubrimiento de la verdad.

Muchas personas se afanan vehementemente por hacer notar que sus análisis, estudios, señalamientos, pero sobre todo propuestas, pueden ser clasificadas dentro de la economía crítica. Quizá lo más cercano a la realidad es que muy pocas personas son capaces de hacer economía crítica. Y aquí habrá que indicar algunas condiciones para poder discernir este punto. Una condición para hacer economía crítica parte, no tanto de la formación académica-teóric, a como de la creencia en la necesidad y sobre todo, la posibilidad, de sustituir el sistema. ¿Cuál sistema? Por supuesto, el sistema 
capitalista vigente a escala global. Indudablemente, esto no es suficiente y es apenas el punto de partida. También se necesita de una formación en corrientes o escuelas económicas heterodoxas. Es decir, se necesita conocimiento y fe.

Una característica importante del hacer, en concordancia con la economía crítica, es que permite darnos cuenta de cuándo y cómo los economistas de la corriente hegemónica - típicamente neoclásica- engañan de forma docta, haciendo uso de una jerga críptica para hablar de las situaciones cotidianas a las que el desarrollo de las fuerzas capitalistas llevan. Es decir, una función característica de la economía crítica es dar a conocer en forma Ilana qué está sucediendo y por qué, y este por qué debería enfocarse en clarificar el uso (abusivo) del poder (económico) expresado en las relaciones sociales asimétricas, las cuales indudablemente llevan una cuota de opresión.

El pensamiento crítico en economía se puede poner en práctica desde lo normativo y desde el lado positivista de la investigación económica. Se apunta siempre a un discurso diferente, crítico en tanto desigual de lo dominante y hegemónico, contrapuesto en la esencia más que en la forma. Un criticismo que responde a la raíz etimológica del término "crítico", Carlos Díaz, en su artículo "Conciencia crítica", escribe: "La conciencia es siempre la realidad que critica en el sentido más etimológico del término: lo que criba, que discierne, que selecciona, que analiza, que sintetiza, que configura y hasta desconfigura"1.

Particularmente, algunos artículos de esta revista tendrán como talante lograr superar la hipercrítica tan sólo mordicante, entendida ésta como la crítica desde la ignorancia y el discurso demagógico cuyo objetivo es más bien conseguir o mantener el poder, para asentarse en la crítica sólidamente fundamentada en el conocimiento. Lo cual por cierto, no implica olvidar la economía ortodoxa, sina aprehenderla y encontrar sus limitaciones.

Sin duda el pensamiento de Marx fue en su época la gran opción heterodoxa al pensamiento de los clásicos. Por algo, el subtítulo de su obra es Crítica de la economía política. Sin embargo, el pensamiento crítico económico no se agota en Marx, ni en los llamados marxistas o neomarxistas (a propósito de los neoclásicos).

Por esta razón es que no debemos entender por heterodoxia una sólo corriente típicamente marxista y centrada en la teoría del valor basada en el trabajo, sino más bien debemos incorporar en el abanico heterodoxo a una gama de pensamientos que, como el arco iris, van del amarillo pálido al 
rojo intenso. Por ejemplo, neoclásicos-liberales, centrados en el conflicto de clases que surge de la producción y distribución; o keynesianos-socialdemócratas, cuyo énfasis está en la capacidad del estado para corregir y redistribuir los frutos del crecimiento. Lo más importante es que todos posean una pretensión de abarcar perspectivas diferentes a las que tienen aquellos que están a favor del sistema, pero, sobre todo, a favor de los poderosos dentro del sistema capitalista vigente actual.

Pensamiento crítico en economía es aquel que está a favor de un cambio de sistema que permita que las relaciones sociales de producción valoricen más al trabajo y menos al capital. En algunas ocasiones esto lleva consigo la necesidad de desafiar el sentido común establecido y plantear reflexiones que intenten "hacerse cargo de la realidad", captando lo que el consenso comunicativo económico-social muestra como su negatividad.

Al decir de Nicolás Casullo, se trata de poner a prueba los saberes ya sancionados y aprobados por la sociedad, particularmente la academia y los centros de poder económico y mediático. La persona que hace economía crítica necesariamente debe hacer surgir una incomodación del sentido común establecido, y al menos debe dejar en el subconsciente de quienes le escuchan o leen ideas que los lleven a vivenciar nuevas formas de ser, de ver, de leer, en suma de interpretar la realidad económica y, ojala, de habérselas con ella.

Una perspectiva crítica no es sólo mostrar disconformidad con el estado presente, sino y sobre todo, lograr que esta crítica del presente permita una otredad de lenguajes diferentes a los hegemónicos, y así contribuir a revertir el pasaje que le toca vivir a la mayoría de la población, sin posibilidad de escapatoria en el sistema capitalista actual.

Y aquí procede pensar en el Ángel de la Historia de Walter Benjamin, el ángel que nos llama a mirar atrás. Ver para atrás y no para adelante para entender desde los débiles que el futuro que se supone adelante no existe para la mayoría, debido a que este movernos hacia ese futuro, no resulta ser un acercamiento a un mejor ser y estar. Es más bien, un alejamiento del paraíso y, además, la pérdida de las utopías, tan necesarias para vivir. Entonces, hay que buscar los anhelos perdidos atrás, los sueños de bienestar, pero desde una mirada radicalmente materialista crítica, no mecanicista, evitando el peligro de prestarse a ser instrumento de la clase dominante.

Para la mayoría de nosotros, resulta que la regla es el estado de excepción, es decir, el estado en que nuestra vida se encuentra permanentemente 
amenazada por la situación que nos configura, la formación económica social que nos oprime, este capitalismo neoliberal que arrincona a la mayoría a la exclusión, y por tanto, a la pobreza.

Para lograr salir de este estado de excepción es imperativo que nos llegue "el asombro acerca de que las cosas que estamos viviendo sean 'todavía' posibles en el siglo XXI, que sea posible la existencia de asentamientos precarios urbanos, o la muerte por intoxicación de granos destinados para la siembra debido a la falta de alimentos, o la muerte por desnutrición, dengue o rotavirus; o la pérdida de vidas humanas debido a la extrema vulnerabilidad que sufre el país; o que existan asentamientos enteros sin acceso a agua potable por días, semanas e incluso meses.

El pasado analizado desde la economía hegemónica, evidencia un camino de lento progreso, medido a través de un crecimiento pobre, pero crecimiento al fin, las proyecciones futuras insisten en el crecimiento y objetivo de lograr competitividad y bajo costo para lograrlo. Esta economía dominante no logra mirar la ruina que se acumula bajo este falso progreso, tampoco cuestiona los fundamentos del sistema vigente.

Los economistas Franz Himkelammert y Henry Mora nos hacen darnos cuenta que lo determinante de la historia, cualquier historia, y del sistema económico, cualquier sistema, es la producción y reproducción de la vida material, de la vida real, pues si la vida corporal no se reproduce cualquier sociedad deja de reproducirse y eventualmente de existir.

En este sentido, lo económico es la "última instancia". Estos autores suelen citar una carta que Engels escribió en septiembre de 1890 a J. Bloch, que dice: "según el concepto materialista de la historia, el momento determinante de la historia es, en última instancia, la producción y reproducción de la vida real".

Esta tesis, obvia e irrefutable, desaparece, de tan clara y transparente, del análisis económico actual. Según este análisis, todos los fenómenos socioeconómicos, sean del tipo que sean, pueden explicarse a partir del comportamiento maximizador. Al mismo tiempo se consagra una especie de determinismo económico neoclásico y neoliberal, que postula que la economía es la "primera instancia" de la vida. En otras palabras: para que haya vida se necesita la economía.

Es decir, se trastoca la condición última, sustituyendo la producción y reproducción de la vida material como condición de existencia de cualquier 
sistema económico-social, por criterios o condiciones cuantitativas expresadas en variables como la tasa de ganancia, o tasa de crecimiento económico y fetichizadas como progreso y desarrollo cuando estas se calculan como positivas.

En el sistema económico en el que sobrevivimos existe una evidente tensión entre la economía como última instancia de producción y reproducción de la vida y, la "economía" como primera instancia de maximización de ganancias, bienestar y crecimiento.

Una tensión entre las fuerzas productivas de la sociedad, entre fuerza de trabajo y medios materiales, entre trabajadores dueños de la fuerza de trabajo y los empresarios dueños de los medios de producción. Esta tensión se evidencia en el descenso del grado en que se satisfacen las crecientes necesidades, materiales y espirituales, de las personas trabajadoras y sus familias, en el deterioro de sus condiciones de trabajo y de vida, en una cada vez más desigual distribución del ingreso, es una cada vez mayor depredación de la naturaleza.

Marx logró evidenciar esta tendencia destructiva del capitalismo que, en su devenir, pone en peligro la vida. Hoy tenemos más evidencia, pero paradójicamente menos consciencia de esto, debido a la colonización de la "ciencia económica neoclásica" en todos los saberes. La ciencia ficción neoclásica, como le llama Rémy Herrera en su libro².

\section{La crítica desde la economía heterodoxa a la ciencia económica neoclásica}

El postulado básico del paradigma neoclásico, según Herrera, se resume en "que los fenómenos socioeconómicos, sean los que sean, sólo pueden explicarse a partir del comportamiento maximizador de los individuos, y que éstos, a través de los mecanismos de mercado, pueden conducir a la sociedad hacia la armonía colectiva".

Todo surge en la reivindicación de la economía como ciencia fuertemente matematizada, y al mismo tiempo con una carga normativa imperativa. El equilibrio general permite, aparentemente, demostrar cómo es posible coordinar las elecciones, supuestamente libres, racionales y movidas por el interés individual, de una multitud de agentes en un marco que incluya todas sus interdependencias.

Toda elección de cualquier agente económico depende de dos situaciones: i) de las características constituidas por la dotación de factores con que 
se cuenta, la función de producción que se logre, y los gustos y preferencias que se tengan, y ii) de la restricción que proviene de la forma de organización social en la que se dan los intercambios, es decir, en las estructuras de mercado, dentro de las cuales el paradigma es la "competencia perfecta".

Bajo ciertas hipótesis, alejadas de la realidad por cierto, se logra una solución de equilibrio con una asignación óptima de recursos. De este núcleo teórico se desprende todos los trabajos y desarrollos teóricos y normativos que corresponden a la teoría neoclásica, y al neoliberalismo como su expresión política.

Lamentablemente este esquema o paradigma excluye fenómenos que se imponen en la realidad, como por ejemplo la existencia de bienes públicos para los que no operan los mecanismos de mercado o las externalidades, es decir no toma en cuenta "las fallas de mercado", con lo cual se justifica la intervención de estado en la economía de mercado, nunca un cambio de modelo o de sistema.

En los últimos años, debido a la implacable tendencia destructiva del sistema, se ha hecho necesario realzar la importancia del Estado en la Política Social, y de aquí la importancia, siempre en el marco del paradigma del mercado, de un sistema universal de protección "social focalizado" en los más pobres (sic).

Estos son apenas dos de los señalamientos que se pueden hacer a los razonamientos, postulados y normas que se derivan de la economía neoclásica, particularmente del neoliberalismo. Hay campo para más, la economía crítica y heterodoxa tiene mucho espacio para desplegarse, y ojala, en algún momento pueda lograr avances en el cambio del sistema.

Notas

1. Citado por Diego Guerrero en su libro Historia del pensamiento económico heterodoxo, páginas 199-200.

2. Herrera, Remy. Estado y crecimiento: contra la ciencia (ficción) neoclásica. Traducción: Diego Guerrero. Maya Editores. Madrid 2010. 